\title{
ESTELA DE GUERRERO DE EL CORONIL (SEVILLA)
}

\author{
A WARRIOR STELA FROM EL CORONIL (SEVILLA)
}

\author{
por
}

\author{
ROCÍO IZQUIERDO DE MONTES y SILVESTRE LÓPEZ JURADO
}

\begin{abstract}
El presente trabajo tiene por objeto dar a conocer una nueva estela de las denominadas en la literatura arqueológica "extremeñas", "decoradas del suroeste" o de "guerrero". La pieza que nos ocupa no presenta característica alguna que la distancie de las conocidas hasta la fecha, pero sí constituye uno de los ejemplares más meridionales de su área de dispersión, sólo superada hacia el sur por otra procedente de las cercanías de Torres Alocaz, en término de Utrera (Oliva y Chasco 1976).

La pieza fue descubierta en 1994 por uno de los autores (S.L.J.) en el término municipal de El Coronil (fig. 1). Las coordenadas del sitio son $37^{\circ} 03^{\prime} 00^{\prime \prime}$ y $5^{\circ} 38^{\prime} 5^{\prime \prime}$. Se encontraba en la orilla derecha del cauce de la Colada de las Aguzaderas, en la confluencia con una cañada de ganado conocida como Vereda de Churriana, en el tramo que discurre desde El Coronil a Las Cabezas de San Juan.

La estela fue realizada en un bloque de piedra arenisca local con forma triangular (fig. 2). La altura máxima de éste es $186 \mathrm{~cm}$, la anchura $110 \mathrm{~cm}$ y el grosor $18 \mathrm{~cm}$. Se encontró tendida, con las figuras grabadas hacia arriba; pero tanto la escena representada, que ocupa las tres cuartas partes superiores de la piedra, como la forma del bloque sugieren una posición original enhiesta, tal como se ha sospechado que irían de hecho todas las estelas de este tipo. De ser el lugar donde ha aparecido el punto primitivo en el que estuvo el monumento, éste debió de tener la cara decorada mirando al noreste, de manera que la representación sería vista por quienes discurrieran hacia el suroeste por la Vereda de Churriana procedentes del punto que actualmente ocupa la localidad de El Coronil.

En el monolito se plasma mediante la técnica del grabado y posterior abrasión de la superficie pétrea, un guerrero con su panoplia. Ha de señalarse que la disposición de los elementos tallados en la piedra no se ha dejado al azar, sino que cada uno de ellos se representa en la posición que su uso requiere. La figura humana, que ocupa la posición central y el protagonismo de la escena, se traza de forma esquemática. Especial énfasis se le da al tratamiento de las manos, cuyo tamaño con relación al del resto del cuerpo se ha exagerado, como ocurre en muchas otras piezas. El personaje está tocado con un casco de cuernos como símbolo de fuerza, poder y valor del guerrero. Alrededor de éste se dispone su panoplia. En su lado derecho, a la altura de la mano, una espada con mango rectangular y extremo inferior muy apuntado. La forma de su hoja permite encuadrar esta variedad en el tipo de "lengua de carpa". También en el lado derecho, pero en la parte superior, a la altura de la cabeza del guerrero, se representa un peine. En el lado izquierdo de la estela se dispone,
\end{abstract}


junto al brazo del individuo, un escudo redondo en el que se han grabado la abrazadera rectangular para asirlo y, mediante el trazo de líneas, los círculos concéntricos que componen la cara externa del escudo. A la derecha de la pieza anterior se dibuja de forma muy esquemática una lanza, de la que no se aprecian ni las características de su punta ni la de su regatón. En un plano inferior hay grabado un trazo que interpretamos como puñal o cuchillo, según los que se representan en otras estelas pero con trazos más semejantes a los modelos reales. La piedra presenta una perforación y otra oquedad que no llega a atravesarla, si bien ambos accidentes parecen naturales, por lo que debieron existir en la roca con anterioridad a que se grabara en ella la escena.

Los estudios que han profundizado en las estelas han sistematizado sus tipos según los elementos representados y su área de distribución. El ejemplar de El Coronil puede integrarse en la clase IIC de Gomes y Monteiro (1977: 186), en el IIC-D de Almagro-Gorbea (1977: 172 y 175), o en el Grupo 6 de Galán (1993: 48-51). El área de dispersión de estas losas se centra en el valle del Guadalquivir.

Los elementos representados no permiten fecharla con excesiva precisión dentro de la época tartésica. Sólo la espada puede proporcionar un margen temporal más concreto. Por ser del tipo llamado "de lengua de carpa", puede fecharse entre los siglos X y VII a.C. según sugiere la cronología del depósito de metales de la Ría de Huelva. Éste se ha tenido a veces por un conjunto cerrado correspondiente a un solo momento, con una datación de los siglos X o IX a.C.; pero existen en él fíbulas anulares que no se fechan en contextos claros en momentos anteriores al VII (Ferrer y otros 1997: 85).

El punto en el que apareció la estela que estudiamos se encuentra situado en la campiña sureste sevillana. Esta zona está compuesta por parte de los términos municipales de El Coronil, Utrera, Morón de la Frontera, El Arahal, Montellano y Los Molares. Los yacimientos protohistóricos documentados más próximos al lugar en el que apareció la estela de El Coronil se conocen a través de las prospecciones realizadas en la zona por Ruiz Delgado (1985: 95-99). Los sitios arqueológicos serían El Amarguillo I al oeste, y Las Aguzaderas, La Esclavitud, La Carrascosa y La Foronguilla al este. Se trata de núcleos de pequeña entidad, a excepción del de Las Aguzaderas. Éste presenta unas condiciones inmejorables para su elección como lugar de hábitat: ubicación sobre una elevación del terreno que le permite un dominio visual del entorno, proximidad a una vía natural de comunicación y control de un manantial de agua potable. Dada la presencia también de materiales arqueológicos fechables en la Edad del Cobre, estas óptimas condiciones tampoco habrían pasado inadvertidas en tiempos calcolíticos. En El Amarguillo I aparecieron sobre la superficie del suelo actual unas manchas oscuras interpretadas como posibles fondos de cabaña, y, asociadas a aquéllas, cerámica y útiles de piedra de época protohistórica.

La ubicación de esta estela en una vía de paso ganadero -la Vereda de Churriana-, en concreto en el cruce de ésta con el Arroyo de las Aguzaderas -hoy seco por la dinamitación de su manantial en los años sesenta del presente siglo-, podría apoyar la hipótesis que considera a las estelas hitos para ser vistos en la distancia por los viandantes e informarles de los recursos controlados por el grupo local (Ruiz-Gálvez y Galán 1991:262-267). En contra de esta interpretación, S. Celestino ha argumentado una serie de razones por las cuales las estelas dudosamente podrían servir de marcadores. Por un lado, su tamaño no demasiado grande impediría verlas con facilidad desde cierta distancia. Además, al ser casi siempre de piedra local, tampoco destacarían de otros monolitos naturales de la zona. En tercer lugar, la proximidad a caminos es algo consustancial a muchas otras actividades humanas, y no es por tanto razón suficiente para adjudicarles una función determinada salvo la que se deriva de su necesidad de ser vista (Celestino 1998: 8-9). La estela de El Coronil se encuentra en una de las rutas propuestas por Ruiz-Gálvez y Galán a través de la que discurrirían ganaderos itinerantes y productos comerciales. Ésta partiría del Sistema Central y, a través de puertos y vados, conectaría con la Vía de la Plata, cruzaría el Guadalquivir y remataría en la costa meridional, teniendo su mojón más meridional en la estela de Torres Alocaz (Ruiz-Gálvez y Galán 1991: 267): Pero en esa hipótesis quedan sin explicar cómo se han representado los recursos controlados y la 
naturaleza de éstos. Por otro lado, el estudio de la zona de influencia de las estelas ha puesto de manifiesto la imposibilidad de aislar el condicionante económico que habría llevado a colocar la losa como medio para señalizar dicho recurso (Galán 1993: 36). De ahí que de nuevo nos parezca oportuno retomar otra de la funciones propuestas para las estelas de guerrero -la funeraria- a pesar de que pueda desecharse su asociación a tumbas en el más estricto significado del término (Galán 1993: 16-17). En este sentido, por su ubicación al pie de cursos de agua o en lugares muy próximos a ellos, podrían interpretarse como marcadores del lugar en el que se ha practicado un rito funerario acuático, en el cual el cuerpo del individuo y quizás su panoplia se arrojaron al agua, quedando en tierra la estela como verdadero cenotafio que recordaba la ceremonia allí realizada. En la piedra habrían quedado inmortalizados los elementos que conferían rango al guerrero y que tal vez le acompañaron en la pira y al otro mundo. Según esto, el tema representado en las estelas estaría más en consonancia con la interpretación funeraria-más evidente en la pieza de Ategua (Bendala 1977)- que con la de marcador de un territorio y de sus recursos económicos. En cualquier caso, la hipótesis de Ruiz-Gálvez y Galán no olvida tampoco, aunque la cree subsidiaria, la interpretación relativa al mundo de la muerte.

En el caso de la estela de El Coronil, su íntima asociación al cauce del Arroyo de las Aguzaderas parece apuntar en la dirección de la hipótesis que ve en las estelas el recordatorio en tierra de un rito funerario que consistió en arrojar los restos del difunto a las aguas. Esta práctica ha sido señalada para la fachada occidental europea (Bradley 1990), y tiene como base la coincidencia en el espacio y en el tiempo de dos tipos de datos: el hallazgo en esos medios acuáticos de armas y otros objetos que parecen corresponder a ajuares personales (Ruiz-Gálvez 1982) y la paralela falta en tierra firme de tumbas sensu stricto (Belén y otros 1991; Belén y Escacena 1995: 102-111).

\section{BIBLIOGRAFÍA}

ALMAGRO-GORBEA, M.(1977): El Bronce Final y el Período Orientalizante en Extremadura (Bibliotheca Praehistorica Hispana XIV). Madrid, Consejo Superior de Investigaciones Científicas.

BELÉN, M. y ESCACENA, J.L. (1995): “Acerca del horizonte de la Ría de Huelva. Consideraciones sobre el final de la Edad del Bronce en el Suroeste Ibérico", en M. Ruiz-Gálvez (ed.), Ritos de Paso y Puntos de Paso. La Ría de Huelva en el Mundo del Bronce Final Europeo, en Complutum (Extra 5): 85-113. Madrid, Editorial Complutense.

BELÉN, M.; ESCACENA, J.L. y BOZZINO, M.I. (1991): "El mundo funerario del Bronce Final en la fachada atlántica de la Península Ibérica. I. Análisis de la documentación", Trabajos de Prehistoria 48: 225-256.

BENDALA, M. (1977): “Notas sobre las estelas decoradas del Suroeste y los orígenes de Tartessos", Habis 8: 177-205.

BRADLEY, R. (1990): The Passage of Arms. An archaeological analysis of prehistoric hoards and votive deposits. Cambridge University Press.

CELESTINO, S. (1998): "Los primeros contactos orientales con el Suroeste de la Península Ibérica y la formación de Tartesos", en J.L. Cunchillos y otros (eds.), Actas del Congreso "El Mediterráneo en la Antigüedad: Oriente y Occidente". Sapanu, Publicaciones en Internet II, http://www.labherm.filol.csic.es. FERRER ALBELDA, E.; GARCÍA FERNÁNDEZ, F.J.; GONZÁLEZ ACUÑA, D.; MUÑOZ GARCÍA, E. y MORO BERRAQUERO, F.J. (1997): “Dos notas sobre el depósito de la Ría de Huelva”, Spal 6: 67-85.

GALÁN, E. (1993): Estelas, Paisaje y Territorio en el Bronce Final del Suroeste de la Península Ibérica, en Complutum, Extra 3. Madrid, Editorial Complutense. 
GOMES, M. V. y MONTEIRO, J. P. (1977): "Las estelas decoradas do Pomar (Beja-Portugal). Estudio comparado", Trabajos de Prehistoria 34: 165-214.

OLIVA, D. y CHASCO, R. (1976): "Una estela funeraria con escudo de escotadura en "U" en la provincia de Sevilla", Trabajos de Prehistoria 33: 387-397.

RUIZ DELGADO, M.M. (1985): Carta Arqueológica de la Campiña Sevillana. Zona Sureste I. Sevilla, Universidad de Sevilla.

RUIZ-GÁLVEZ, M. (1982): “Nueva espada dragada en el río Ulla. Armas arrojadas a las aguas”, Homenaje a Alfredo García Alén: 3-18. Pontevedra, Museo de Pontevedra.

RUIZ-GÁLVEZ, M. y GALÁN, E. (1991): "Las estelas del Suroeste como hitos de vías ganaderas y rutas comerciales", Trabajos de Prehistoria 48: 257-273. 


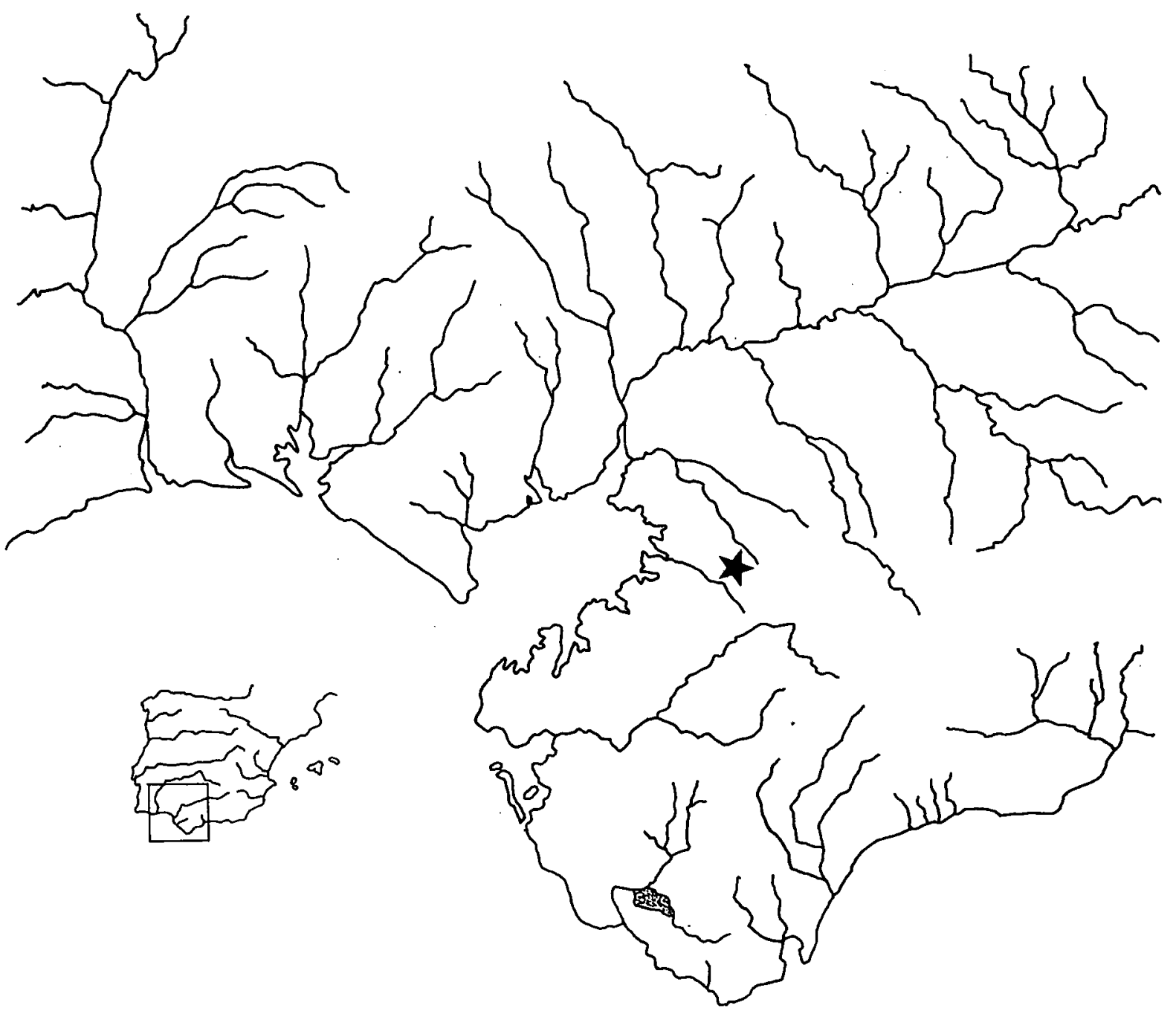

Fig. 1: Ubicación de la estela y reconstrucción de la paleodesembocadura del Guadalquivir en época tartésica. 


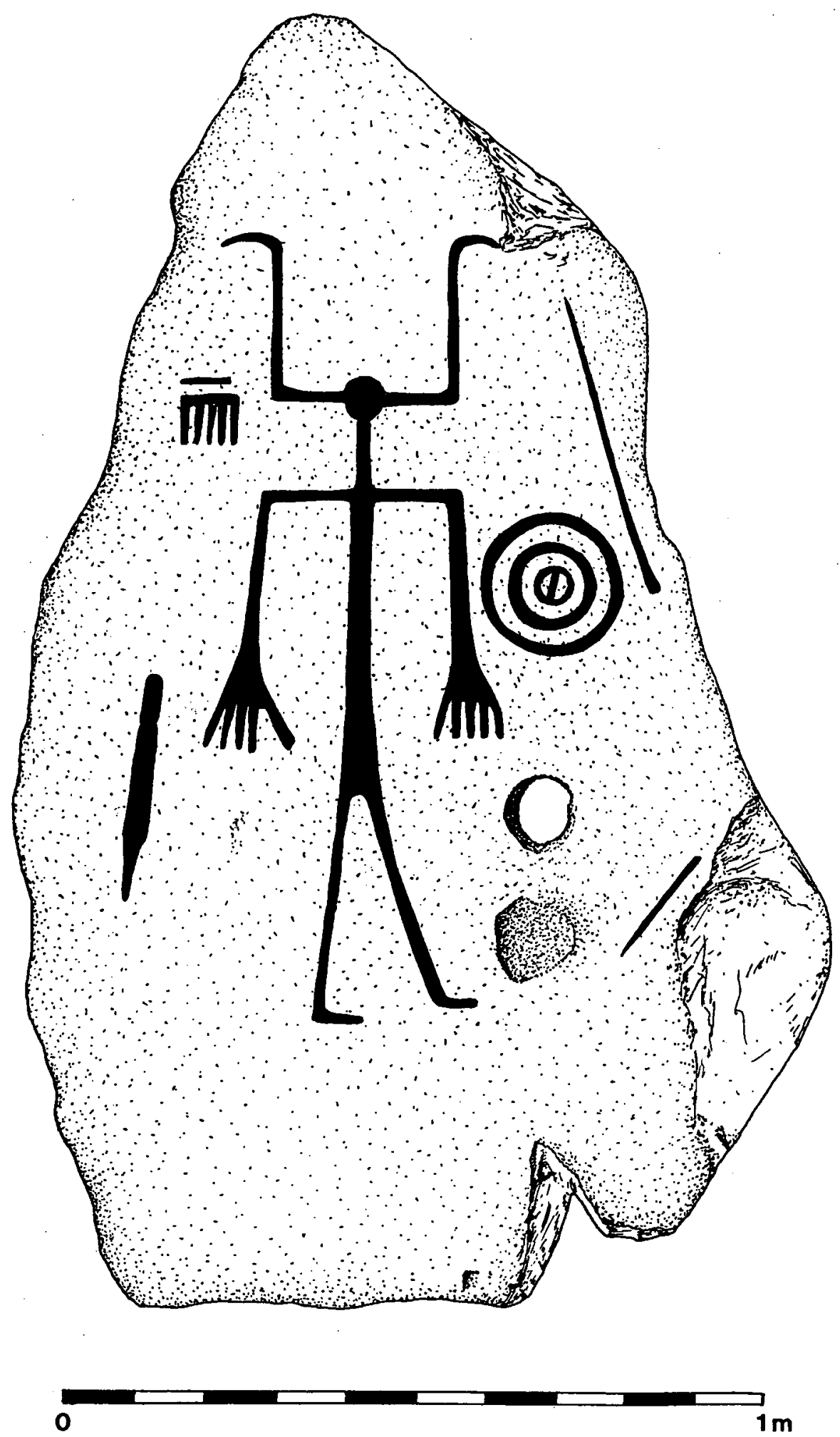

Fig. 2: Estela de El Coronil. 